\title{
Active Flow Control using Sweeping Jet Actuators on a Semi-Span Wing Model
}

\author{
LaTunia Pack Melton* and Mehti Koklu ${ }^{\dagger}$ \\ NASA Langley Research Center, Hampton, Virginia, United States of America
}

\begin{abstract}
Wind tunnel experiments were performed using active flow control on an unswept semispan wing model with a $30 \%$ chord trailing edge flap to aid in the selection of actuators for a planned high Reynolds number experiment. Two sweeping jet actuator sizes were investigated to determine the influence of actuator size on the active flow control system efficiency. Sweeping jet actuators with orifice sizes of $1 \mathrm{~mm} \times 2 \mathrm{~mm}$ and $2 \mathrm{~mm} \times 4 \mathrm{~mm}$ were selected because of the differences in actuator jet sweep angle. The parameters that were varied include actuator momentum, freestream velocity, and trailing edge flap deflection angle. Steady and unsteady pressure data, Particle Image Velocimetry data, and force and moment data were acquired to assess the performance of the two actuators. In addition to the wind tunnel experiments, benchtop studies of the actuators were performed to characterize the jets produced by each actuator. Benchtop investigations of the smaller actuator reveal that the jet exiting the actuator has a reduced sweep angle compared to published data for larger versions of this type of actuator. The larger actuator produces an oscillating jet that attaches to the external diffuser walls at low supply pressures and produces the expected sweep angles. The AFC results using the smaller actuators show that while the actuators can control flow separation, the selected spacing of $3.3 \mathrm{~cm}$ may be too large due to the reduced sweep angle. In comparison, the spacing for the larger actuators, $6.6 \mathrm{~cm}$, appears to be optimal for the Mach numbers investigated. Particle Image Velocimetry results are presented and show how the wall jets produced by the actuators cause the flow to attach to the flap surface.
\end{abstract}

\section{Nomenclature}

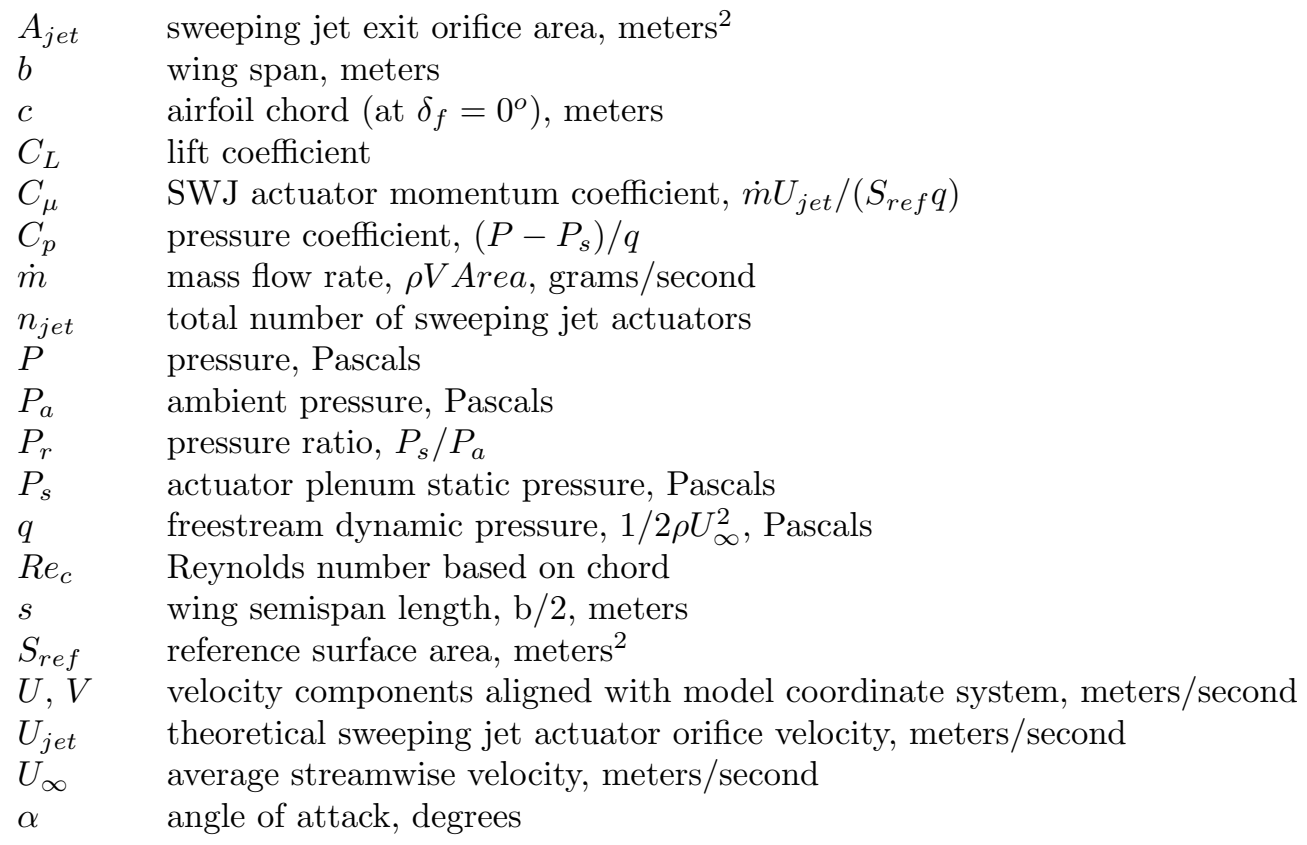

*Research Scientist, Flow Physics and Control Branch, Associate Fellow AIAA

${ }^{\dagger}$ Research Scientist, Flow Physics and Control Branch, Member AIAA 
$\delta_{f} \quad$ flap deflection angle, degrees

$\rho \quad$ density, kilograms $/$ meter $^{3}$

$\xi / c \quad \mathrm{x}$ normalized by chord and rotated

$\psi / c \quad$ z normalized by chord and rotated

$\Omega^{\prime} \quad$ spanwise vorticity $* c / U_{\infty}$

\section{A. Abbreviations}

2D two dimensional

$3 \mathrm{D} \quad$ three dimensional

AFC active flow control

AR aspect ratio

BART Basic Aerodynamics Research Tunnel

LaRC Langley Research Center

PIV particle image velocimetry

SLA stereolithography

SWJ sweeping jet

\section{Introduction}

NE of the goals of the NASA Advanced Air Transport Technology (AATT) Project is to study and advance technologies that have the potential to improve the performance (reduce noise, reduce fuel burn, etc.) of future vehicles used for commercial transport. Active flow control (AFC) is currently being studied because of its potential to improve lift and reduce drag. One of the AFC projects funded by AATT focuses on improving the efficiency of a high-lift system, which, in turn, requires an actuation system that is optimized for efficiency, in terms of power.

Fluidic oscillators have been used in several recent AFC experiments because of their design simplicity and control authority they provide. They have been proven to be effective in controlling flow separation, thereby improving the aerodynamic performance of helicopter fuselages,${ }^{1}$ trucks, ${ }^{2}$ bluff bodies, ${ }^{3}$ wind turbine blades, ${ }^{4}$ airfoils, and wings. ${ }^{5}$ Sweeping jet actuators are a type of fluidic oscillator with no diverter at the actuator exit, therefore the jet exiting the actuator sweeps from side to side. Gregory and Tomac ${ }^{6}$ provide a review of the device that describes its numerous uses including its current use for AFC applications. Recent AFC demonstrations that used sweeping jet actuators include a full-scale AFC-enhanced vertical tail project consisting of a wind tunnel test to advance the technology ${ }^{7,8}$ followed by a flight test. ${ }^{9}$

Vatsa et al. ${ }^{10}$ presented both computational and numerical results on two sweeping jet actuators. The width and height of each actuator was $6.35 \mathrm{~mm}$, making the aspect ratio (ratio of actuator orifice width and height) one. The authors showed that an actuator with a curved internal geometry produced a jet that had a large sweep angle resulting from the wall attachment process that led to the jet spending more time near the diverging walls at the exit of the actuator. The authors suggested that the curved actuator geometry had the potential to be a better flow control device. An experimental study performed by Koklu and Melton ${ }^{11}$ using the same curved actuator geometry provided additional information about the characteristics of the actuator including the time-dependent behavior of the jet.

In a recent experiment, Koklu ${ }^{12}$ performed a parametric study using curved-style sweeping jet actuators that varied in aspect ratio, size, location, and pitch angle to control separated flow on an adverse pressure gradient ramp model. He found that the larger actuators with an aspect ratio of 2 were more efficient at controlling flow separation. The efficiency of the larger actuators was due to both spacial coverage and the streamwise vortices produced by the actuators. Seele et al. ${ }^{13}$ examined the effect of sweeping jet actuator size and spacing on controlling separation on a $12 \%$ thick generic vertical tail model. They obtained a larger increment in side force when using actuators with a larger exit orifice area. The superior performance of the larger actuator compared to the smaller ones was attributed to the smaller actuators reaching sonic conditions sooner than the larger actuators. The authors showed that the sweep angle of the jet exiting the actuator was reduced when the actuator reached sonic conditions. They reasoned that the reduced sweep angle was due to the fact that a sonic jet entrains less flow than a subsonic jet.

This research is a follow-on activity to the study performed in Ref. 5 on the swept configuration of the 
semi-span model with a NACA 0015 cross section. In that study, Melton ${ }^{5}$ found that sweeping jet actuators could be used to reattach the separated shear layer to the surface of the flap even at the model's maximum flap deflection angle of 40 degrees. Previously, zero-net mass flux actuators were shown to be unable to produce any meaningful improvement in lift on the swept configuration. ${ }^{14}$ While the SWJ actuators investigated were able to control separation on the swept configuration, the momentum required was high. The results presented in this paper are part of an effort to reduce the momentum required for effective control of separation when using this sweeping jet actuator geometry. Two actuator sizes are examined. The actuators used are scaled versions of the curved actuator used in Ref. 10 and Ref. 11. Surface pressure data, particle image velocimetery, and balance force and moment data are used to assess the performance of each actuator.

\section{Experiment Description}

\section{A. Wind Tunnel Description}

The experiments were conducted in the NASA Langley Research Center (LaRC) Basic Aerodynamics Research Tunnel (BART). This open-circuit tunnel has an 11:1 contraction ratio and a test section that is 0.71 $\mathrm{m}$ high by $1.02 \mathrm{~m}$ wide by $3.05 \mathrm{~m}$ long. BART is used primarily as a flow physics facility; therefore, it has the instrumentation and optical access needed for measurement techniques such as Laser Doppler Velocimetry (LDV) and Particle Image Velocimetry (PIV). The maximum velocity of the tunnel is approximately $60 \mathrm{~m} / \mathrm{s}$ and we tested at speeds up to $50 \mathrm{~m} / \mathrm{s}$.

\section{B. Model Description}

The model tested is an unswept semi-span wing with a chord of 0.305 meters, a span of 0.610 meters, and a NACA 0015 airfoil cross-section that was built for sidewall AFC testing in the BART facility. ${ }^{14-16}$ Figure 1(a) shows a sketch of the model installation. The wing, shown in Fig. 1 has a $30 \%$ chord trailing edge flap that can be tested at flap deflection angles, $\delta_{f}$, from $-10^{\circ}$ to $40^{\circ}$ in $10^{\circ}$ increments. The $0.610 \mathrm{~m}$ span flap is split into three equal-span components that can be deflected independently. The model had four rows of streamwise pressure taps at spanwise $(y / s)$ locations of $0.17,0.50,0.83$, and 0.99 and four rows of spanwise pressure taps at streamwise $(x / c)$ locations of $0.0050,0.30,0.77$, and 1.0. There are also 12 unsteady pressure transducers connected to orifices on the model surface. The second version of the General Aviation Circulation Control balance, a 5-component strain gage balance, was used to measure forces and moments on the model. The balance axial and yawing moment limits prevented testing at high angles of attack and high dynamic pressures. Therefore, the results presented are limited to angles of attack near stall.

During the sweeping jet actuator study using the swept wing version of the model, ${ }^{5}$ the aft region was modified so that sweeping jet actuators could be integrated into the main element at the flap shoulder. However, the small size of this region limited options for testing different actuator configurations. For the current set of experiments, a new upper spar was manufactured enabling the aft section of the main spar to be removed and replaced with various actuator configurations. The new actuator sections were made using high-resolution sterolithography (SLA). Figure 1 shows a CAD image of the modified model.

\section{SWJ Actuators}

The high-resolution SLA actuator modules were built in three sections. Each section was $0.203 \mathrm{~m}$ and covered the span of a flap section. The SWJ actuators selected for this study are scaled versions of the one used in the study by Koklu and Melton, ${ }^{11}$ which had an aspect ratio of 1 . We used actuators that had an aspect ratio of 2:1. This ratio was chosen because Koklu and Owens ${ }^{17}$ found that it was the most effective at controlling separation on their ramp model. We investigated actuators with orifices that were 1 $\mathrm{mm}$ high by $2 \mathrm{~mm}$ wide and actuators that were twice this size, $2 \mathrm{~mm}$ high by $4 \mathrm{~mm}$ wide. These actuator sizes were chosen for two reasons. First, the smaller actuator corresponds to the size that will be used on an upcoming high Reynolds number separation control experiment. Second, the larger actuator performs more like the actuator that was investigated experimentally by Koklu and Melton ${ }^{11}$ and experimentally and computationally by Vasta et al. ${ }^{10}$ The actuators with an orifice size of $1 \mathrm{~mm}$ high by $2 \mathrm{~mm}$ wide were spaced $3.3 \mathrm{~cm}$ apart and six actuators were installed in each SLA section. The larger actuators were spaced $6.6 \mathrm{~cm}$ apart and three actuators were installed in each SLA section. These actuator spacings are similar to what 


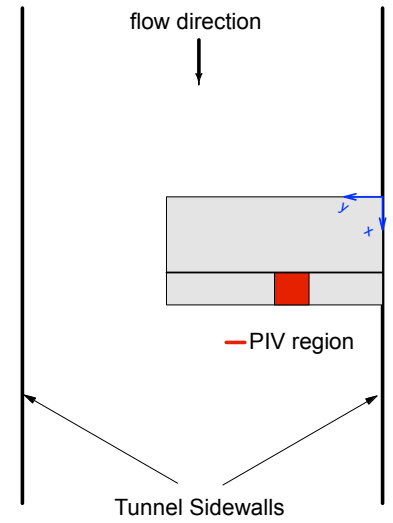

(a) Sketch of wing installation.

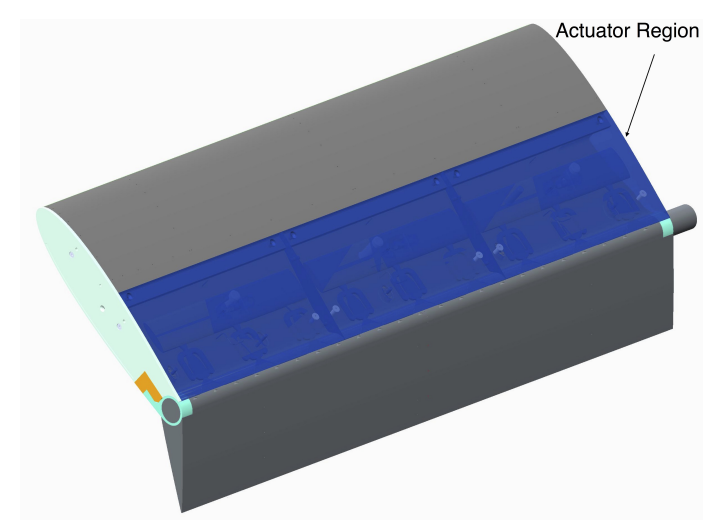

(b) CAD image of model with actuator region shown in blue.

Figure 1. Semi-span wing model description.

will be used during the upcoming high Reynolds number wind tunnel experiment.

The oscillation frequency of a sweeping jet is dependent on the mass flow supplied to the actuator. To verify that the actuators were performing properly, we measured the actuator plenum pressure and frequency at the exit of the actuator for varying mass flow rates. For the smaller actuators, we used a hotwire to measure the output and for the larger actuators we used an unsteady total pressure probe. The unsteady total pressure probe was used with the larger actuator because the measurements were acquired with the model in the tunnel so the hardware used for wind tunnel data acquisition could be used. The unsteady pressure sensors embedded in the flap of the model verified that the actuator, at least the one closest to the pressure sensor, was oscillating at the expected frequency throughout the test. Figure 2 shows the frequency generated by each size actuator as a function of pressure ratio, $P_{r}$, which is the actuator plenum static pressure normalized by the ambient pressure. For our test conditions, the smaller actuator has a maximum frequency of about $1900 \mathrm{~Hz}$ and the larger actuator has a maximum frequency of about $700 \mathrm{~Hz}$.

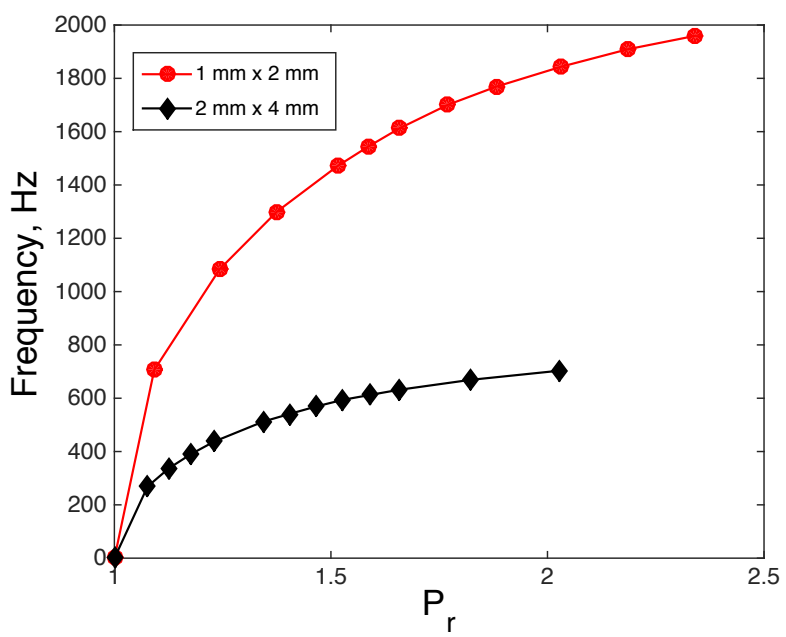

Figure 2. Actuator frequency as a function of $P_{r}$.

The jet produced by each actuator exited the model at the flap shoulder and was nearly tangential to the flap surface when the flap deflection angle, $\delta_{f}$, was $0^{\circ}$. The actuators were integrated into the new SLA parts so that the outer mold line of the model did not change. Since the slot height of the original model was $0.76 \mathrm{~mm}$, the diffuser of each actuator was designed to converge to this height at the actuator exit. 


\section{Particle Image Velocimetry}

Two, two-dimensional (2D) PIV systems each comprised of a pulsed Nd:YAG laser operated at $10 \mathrm{~Hz}$, a 2048 x 2048 camera with a camerlink interface, and acquisition software written by Wernet, ${ }^{18}$ were used to acquire the PIV data. One camera was used to acquire data in the streamwise, $x$, direction on the flap surface while the other was used to acquire data in the spanwise, $y$, direction on the flap. A $105 \mathrm{~mm}$ macro lens was used with the streamwise camera, and the field of view was $183 \mathrm{~mm}$ x $183 \mathrm{~mm}$. A $200 \mathrm{~mm}$ macro lens was used with the spanwise camera, and the field of view was $79 \mathrm{~mm} \times 79 \mathrm{~mm}$. We recognize that a stereoscopic PIV system should be used when acquiring the spanwise PIV data due to the large out-of-plane component of velocity. However, a 2D system was used to provide qualitative information and determine if the vortices produced by the sweeping jet actuators could be detected before investing the time and resources into a stereoscopic system. Laser light guide arms and commercial off-the-shelf light sheet forming optics modules were used to generate both the streamwise and spanwise lightsheets. The data were processed using commercially available PIV analysis software. ${ }^{19}$ The interrogation window was 24 pixels x 24 pixels (2.14 $\mathrm{mm} \times 2.14 \mathrm{~mm}$ ) with an overlap of $50 \%$ for the streamwise system. An interrogation window size of 32 pixels x 32 pixels $(2.47 \mathrm{~mm} \times 2.47 \mathrm{~mm})$ with an overlap of $50 \%$ was applied to the data from the spanwise PIV system. To increase the streamwise field of view, the camera, located on the side of the tunnel opposite the balance, was rotated so that the flap surface was horizontal in the camera view. Streamwise planes of PIV data were acquired at multiple $y / s$ locations. Figure 3(a) shows the four spanwise locations and Fig. 3(b) shows the eight spanwise locations where PIV surveys were acquired relative to the SWJ actuator position. Figure 3(c) shows the streamwise locations along the flap where spanwise planes of data were acquired. The flowfield was seeded with 1 micron particles produced by a theatrical smoke generator. For the data presented, 800 image pairs were used to compute the mean values. The PIV data were acquired with the flap deflected to $40^{\circ}$ and the model angle of attack set at either $6^{\circ}$ or $8^{\circ}$.

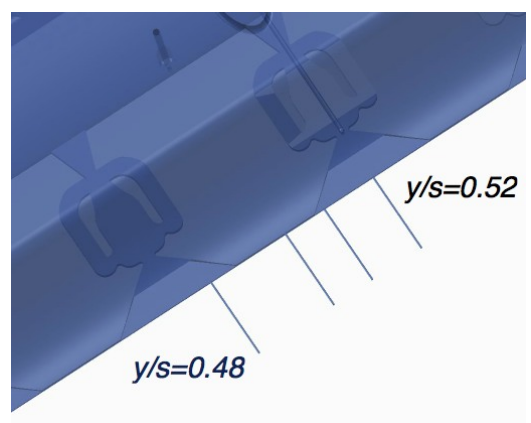

(a) Close-up view of the bottom of $1 \mathrm{~mm} \times 2 \mathrm{~mm}$ actuator. PIV survey planes are denoted by the four lines protruding from the trailing edge of the SLA part.

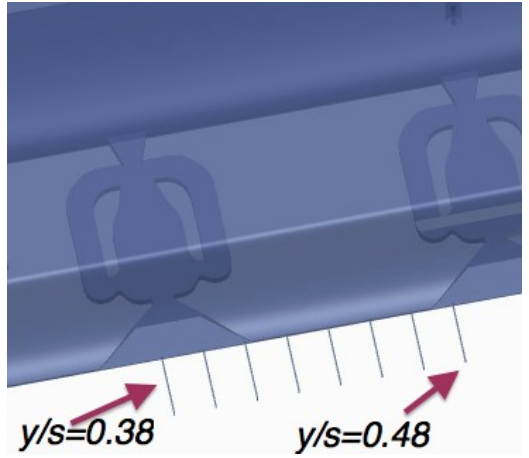

(b) Close-up view of the bottom of $2 \mathrm{~mm} \times 4 \mathrm{~mm}$ actuator. PIV survey planes are denoted by the eight lines protruding from the trailing edge of the SLA part.

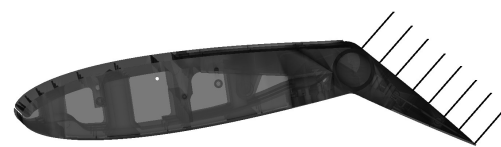

(c) Sketch showing spanwise PIV plane locations.

Figure 3. Description of particle image velocimetry streamwise and spanwise measurement regions.

\section{Benchtop Results}

Benchtop experiments were performed using individual SWJ actuators to characterize the jets produced by the $1 \mathrm{~mm} \times 2 \mathrm{~mm}$ actuator and the $2 \mathrm{~mm} \times 4 \mathrm{~mm}$ actuator. Schlieren flow visualization data, hotwire data and total pressure data were acquired at the exits of the two actuators. Contours of mean total pressure for the $1 \mathrm{~mm} \times 2 \mathrm{~mm}$ sweeping jet actuators are presented in Fig. 4 and show the effect of increasing the pressure, and thus mass flow, supplied to the actuator. The lowest input pressure tested shown in Fig. 4(a) produces a jet that has the highest sweep angle of $57^{\circ}$. As the pressure is increased, the sweep angle reduces to $30^{\circ}$ and $23^{\circ}$ for the supply pressures shown in Fig. 4(b) and Fig. 4(c), respectively. The sweep angle trends from the pressure contour data agree with schlieren flow visualization data (not shown) and eliminate probe interference as a possible source of error.

While the changes in sweep angle with supply pressure have been documented in previous studies, ${ }^{13}$ the 
small sweep angle of this actuator at the lowest input setting is not as well documented. Koklu ${ }^{12}$ presented exit profiles comparing the two actuators used in this study. He noted a narrower exit profile for the small actuator compared to the larger actuator. Melton ${ }^{5}$ also noted that the smaller actuators do not have the same performance as the larger actuator used in Ref. 10 and Ref. 11. The maximum jet sweep angle in this study of $57^{\circ}$ for the $1 \mathrm{~mm}$ x $2 \mathrm{~mm}$ actuator is smaller than the total exit angle of the actuator diffuser which is $100^{\circ}$. At low supply pressures, the jet exiting the actuator of Ref. 10 and Ref. 11 with a $6.35 \mathrm{~mm}$ x $6.35 \mathrm{~mm}$ orifice attaches to the diffuser walls of the actuator, thus the jet sweep angle is at least $100^{\circ}$. Similar pressures surveys and schlieren data were acquired at the exit of the $2 \mathrm{~mm} \times 4 \mathrm{~mm}$ actuator. The data indicate that the jet exiting the actuator attaches to the diffuser walls of the actuator at low supply pressures and has a jet sweep angle of more than $100^{\circ}$. However, with increasing supply pressure, the sweep angle of the larger $(2 \mathrm{~mm} \times 4 \mathrm{~mm})$ actuator is also reduced. In particular, at a $P_{r}$ of 2.0, the jet sweep angle decreases to $46^{\circ}$. During our tests with the larger actuators the maximum $P_{r}$ was approximately 1.5. The jet in this case attaches to the walls of the exit diffuser generating an expected sweep angle of $100^{\circ}$.

One implication of the benchtop experiments with the smaller actuator is that actuator spacing based on the assumption that the actuator produces a jet with a larger sweep angle could lead to an actuator configuration that is not optimized. Furthermore, as mentioned by Seele et al., ${ }^{13}$ designing an AFC system where the actuators operate at sonic conditions reduces the efficiency of the system due to the reduction in sweep angle that occurs as the supply pressure increases. These are additional reasons for investigating how these two actuators control flow separation due to the large adverse pressure gradient resulting from deflecting the flap on the semi-span model.

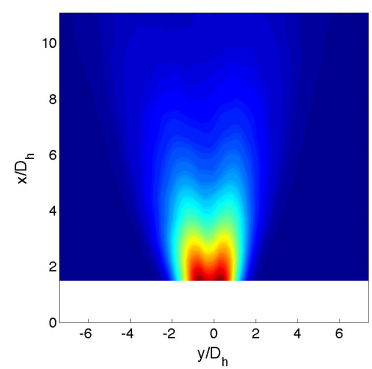

(a) $P_{r}=1.3$.

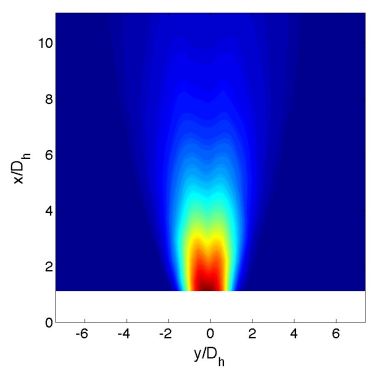

(b) $P_{r}=1.8$.

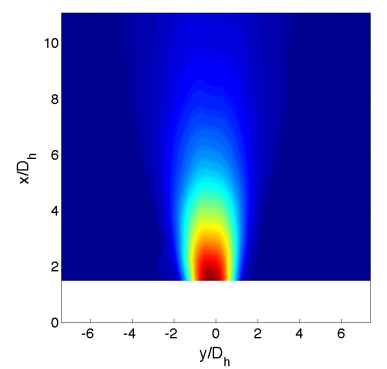

(c) $P_{r}=\mathbf{2 . 2}$.

Figure 4. Contours of total pressure for the $1 \mathrm{~mm} \times 2 \mathrm{~mm}$ SWJ actuator.

\section{AFC Results}

As mentioned previously, one of the goals of the experiments performed with the NACA 0015 was to determine if the SWJ actuators with an orifice size of $1 \mathrm{~mm}$ high x $2 \mathrm{~mm}$ wide and a spanwise spacing of $3.3 \mathrm{~cm}$ would be effective at controlling separation on the trailing edge flap of the model. This study was done in support of a planned high Reynolds number separation control experiment where the existing model geometry drives the size and spacing of the actuators. The benchtop results presented in the previous section showed that there were deficiencies in the performance of the small actuator as indicated by the reduction in the jet sweep angle. In this section, we present wind tunnel results to assess the performance of the two sweeping jet actuators. While most of the test focused on determining the effectiveness of the small actuator, the larger actuator was also investigated at $\delta_{f}=40^{\circ}$ for comparison.

\section{A. $1 \mathrm{~mm} \times 2 \mathrm{~mm}$ SWJ Actuator, $\delta_{f}=20^{\circ}$}

We began our study by testing the baseline (no flow control applied) model with the flap undeflected. We verified that the streamwise $C_{p}$ measurements (not shown) with the new upper spar and aft SLA actuator sections agreed with those acquired in previous studies. ${ }^{14,15}$ In general, there was good agreement between the two data sets, with the largest difference being at the $\mathrm{y} / \mathrm{s}=0.99$ location. These differences may be due to the larger step noticed between the outboard edge of the model and the endcap of the model. Similar checks were done with a flap deflection of $20^{\circ}$. Transition dots were then added to the model with $\delta_{f}=20^{\circ}$ 


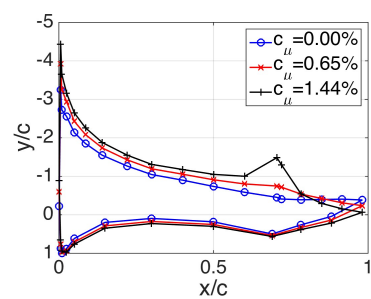

(a) $\mathrm{y} / \mathrm{s}=\mathbf{0 . 1 7}$

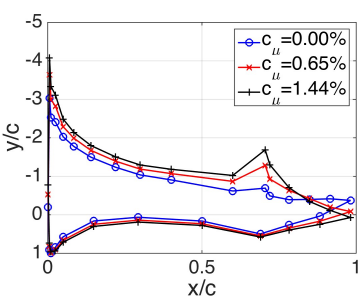

(b) $\mathrm{y} / \mathrm{s}=\mathbf{0 . 5 0}$

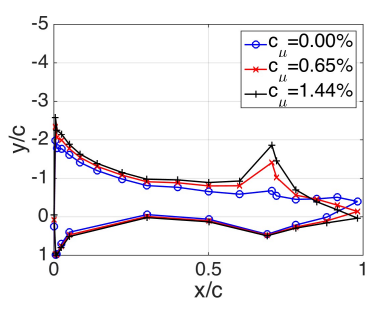

(c) $\mathrm{y} / \mathrm{s}=\mathbf{0 . 8 3}$

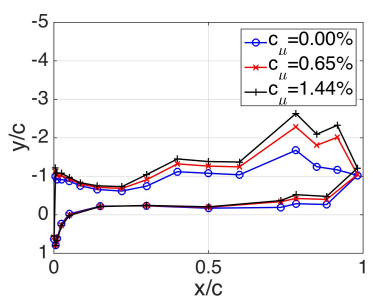

(d) $\mathbf{y} / \mathbf{s}=\mathbf{0 . 9 9}$

Figure 5. $C_{p}$ data at $R e_{c}=\mathbf{5 0 0 , 0 0 0 ,} \delta_{f}=20^{\circ}$, and $\alpha=6^{\circ}$.

and remained on the model throughout the test. The transition dots were added to eliminate some of the low Reynolds number effects that were seen at low angles of attack.

The $C_{p}$ distributions presented in Fig. 5 describe the chordwise pressure distributions at four locations along the span of the model with the flap deflected to $20^{\circ}$ and the model at an angle of attack, $\alpha$, of $6^{\circ}$. In the unswept configuration, the tip vortex aids in controlling separation on the outboard portion of the wing (Fig. 5(c) and Fig. 5(d)). The smaller suction peaks at the $\mathrm{y} / \mathrm{s}=0.83$ and $\mathrm{y} / \mathrm{s}=0.99$ locations are indications that less lift is generated in these locations along the model span. The plateaus in the pressure along the flap surface $(x / c>0.70)$ at $y / s=0.17,0.50$, and 0.83 indicate that the flow separates on the flap for the baseline $\left(C_{\mu}=0.0 \%\right)$ case. Active flow control cases using $C_{\mu}=0.65 \%$ and $C_{\mu}=1.44 \%$ are also presented in Fig. 5 and illustrate the ability of the sweeping jet actuator arrays upstream of the flap shoulder to attach the flow to the surface of the flap. Larger $C_{\mu}$ levels could have been presented but the maximum level selected is close to the level where the trailing edge $C_{p}$ has reached zero for the three most inboard $(\mathrm{y} / \mathrm{s}=0.17,0.50$, and $0.83)$ pressure orifice locations.

The sweeping jet actuator AFC results shown in Figure 5 are with a model configuration $\left(\delta_{f}=20^{\circ}\right.$ and $\alpha=6^{\circ}$ ) that was previously tested using zero-net-mass-flux (ZNMF) actuators. Greenblatt and Washburn ${ }^{14}$ used external ZNMF actuators on this model configuration and achieved a $\Delta C_{L}$ of approximately 0.3 using a $C_{\mu}$ value of $1.4 \%$. The SWJ actuator $C_{\mu}$ values of $0.65 \%$ and $1.44 \%$ produce lift increments, $\Delta C_{L}$ values, of 0.2 and 0.4 , respectively. Melton et al. ${ }^{20}$ used ZNMF actuators in a 2D test of this model configuration and showed that a $C_{\mu}$ value of $1.5 \%$ was needed to achieve a pressure recovery similar to that shown in Fig. 5(b). In Ref. 14 and Ref. 20, $C_{\mu}$ is defined based on the peak jet velocity. For this study, thermal mass flow meters were used to measure flow rate and the jet velocity is defined by Eq. 1, where, $A_{j e t}$ is the actuator orifice area $\left(2 \mathrm{~mm}^{2}\right.$ or $8 \mathrm{~mm}^{2}$ ) and density is computed using isentropic relations. Several recent SWJ actuator AFC studies ${ }^{7,8}$ have used similar definitions for $C_{\mu}$. Variations of this definition have also been used where density, $\rho$ is assumed to be constant.

$$
\begin{aligned}
U_{j e t} & =\frac{\dot{m}}{\rho n_{j e t} A_{j e t}} \\
C_{\mu} & =\frac{\dot{m} U_{j e t}}{q S_{r e f}}
\end{aligned}
$$

We present lift polars in Fig. 6 for the model at a flap deflection of $20^{\circ}$ and show that the smaller actuators $(1 \mathrm{~mm} \times 2 \mathrm{~mm})$ are able to increase lift over the entire angle of attack range investigated. Stall occurs for the baseline model at an angle of attack of $12^{\circ}$. The $C_{L}$ values presented are from balance measurements. The data were acquired at $R e_{c}=750,000$ and the highest $P_{r}$ value needed for control was 1.5.

\section{B. $1 \mathrm{~mm} \times 2 \mathrm{~mm}$ SWJ Actuator, $\delta_{f}=40^{\circ}$}

In Figure 7, the increment in $C_{L}$ due to $\mathrm{AFC}$ is presented for the flap deflection of $40^{\circ}$ case. The $C_{L}$ values are from balance data and illustrate that the sweeping jet actuators with an orifice size of $1 \mathrm{~mm} \times 2 \mathrm{~mm}$ are effective at controlling flow separation at this flap deflection angle. At a $R e_{c}$ of 750,000 and Mach number of 0.1 , a $C_{\mu}$ level of $2.9 \%$ provides a lift increment of approximately 0.4 over the angle of attack range tested. Compared to the lower flap deflection case, higher momentum values are needed to achieve comparable increments in lift. Similar results were obtained using ZNMF AFC when testing the 2D configuration of the model with $\delta_{f}=40^{\circ}$ at lower Reynolds numbers. ${ }^{20}$ A $P_{r}$ of 2.3 was needed to achieve the $C_{\mu}=2.9 \%$ 


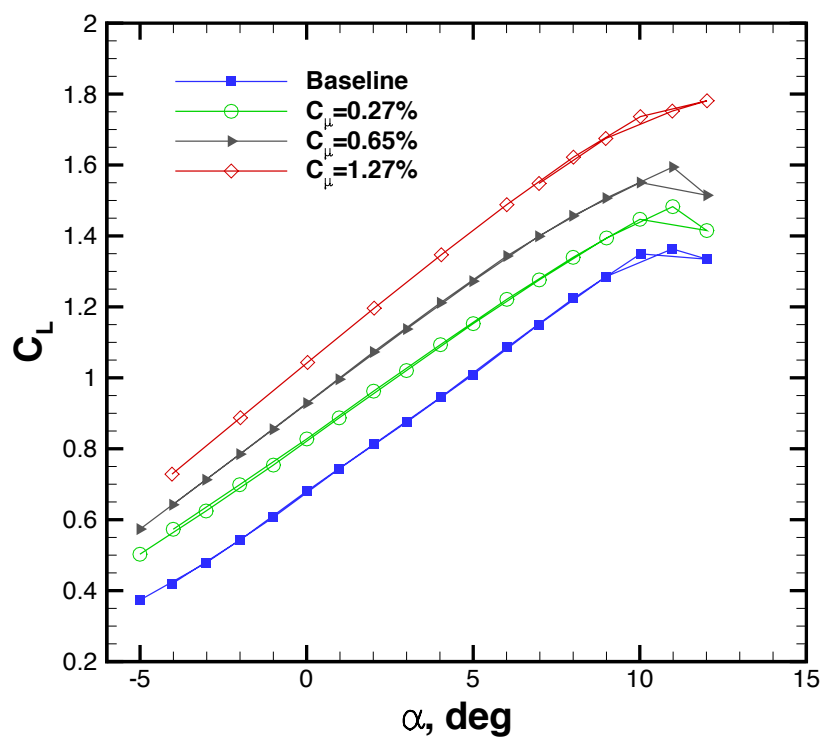

Figure 6. Lift as a function of angle of attack using $1 \mathrm{~mm} \times 2 \mathrm{~mm} \mathrm{SWJ}$ actuators with $\delta_{f}=20^{\circ}$ at $\mathrm{M}=0.1$ and $R e_{c}=\mathbf{7 5 0 , 0 0 0}$.

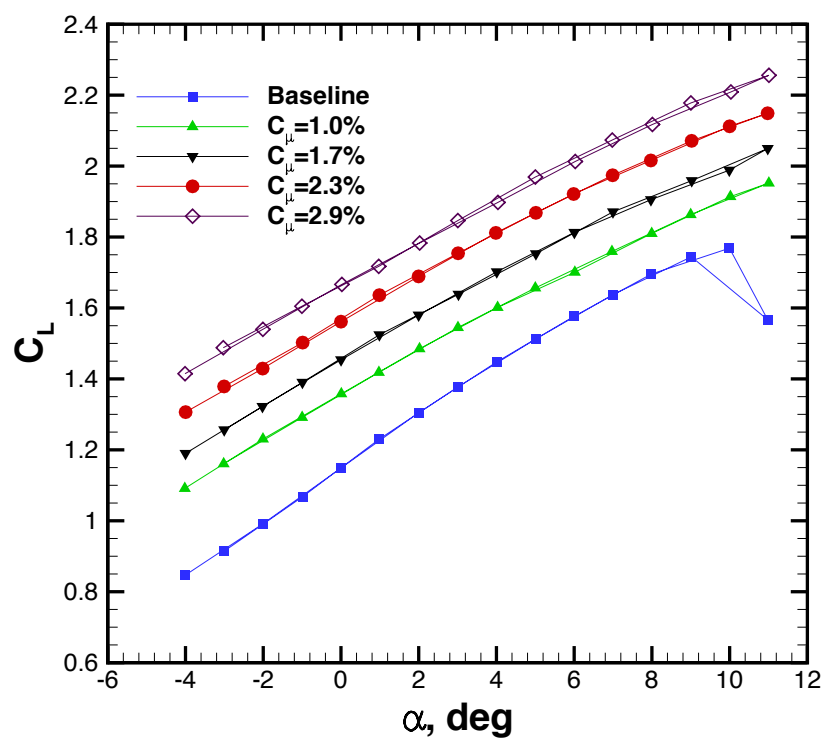

Figure 7. Lift as a function of angle of attack using $1 \mathrm{~mm} \times 2 \mathrm{~mm} \mathrm{SWJ}$ actuators with $\delta_{f}=40^{\circ}$ at $\mathrm{M}=0.1$ and $R e_{c}=750,000$. 
values used for the highest $C_{\mu}$ case presented in Fig. 7. At this condition, the sweeping jet is near sonic conditions and thus the sweep angle of the jet is small. For the planned high Reynolds number AFC wind tunnel test, the Mach number will be much higher. Higher Mach numbers will require even higher pressure ratios meaning the actuators will have to run at sonic conditions. An additional concern with this actuator configuration is that we experienced cases where the sweeping jets could not maintain attached flow over the flap. This was most evident near the streamwise row of pressure orifices located at $y / s=0.5$. This, we believe, is due to the spacing between actuators being too large for this size actuator. Limited PIV surveys between two adjacent actuators (Fig. 8) show regions of separated flow between the actuators. The data were acquired at an angle of attack of $6^{\circ}$. Fig. 8(a) shows vorticity contours at the center of a sweeping jet actuator $(\mathrm{y} / \mathrm{s}=0.52)$, and the flow is more separated than the results shown in Fig. 8(b) and Fig. 8(c). Fig. 8(c) shows results obtained near the pressure orifices at $y / s=0.5$ and Fig. 8 (d) shows results obtained at $y / s=0.48$, where most of our PIV data were acquired. These results suggest that the spacing between actuators may be too large for this size actuator. They also indicate that the PIV measurements at $y / s=0.48$ will tend to show more separated flow compared to the pressure data at $y / s=0.5$.

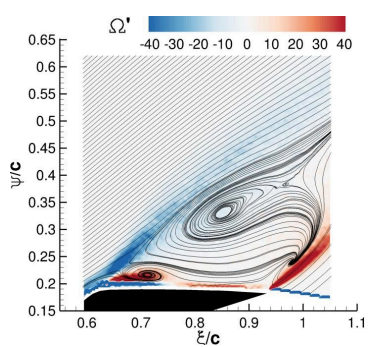

(a) $y / s=0.52$.

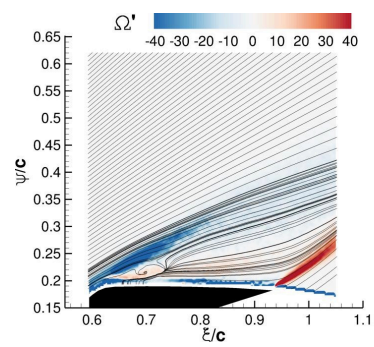

(b) $y / s=0.51$.

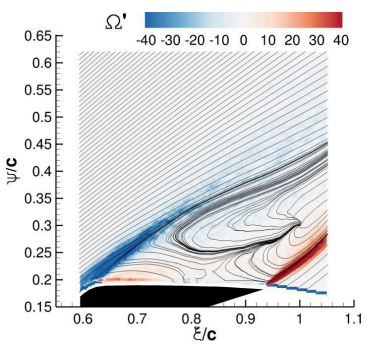

(c) $y / s=0.50$.

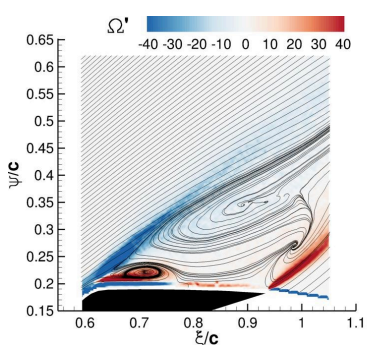

(d) $y / s=0.48$.

Figure 8. Mean vorticity contours from PIV data on the flap using $1 \mathrm{~mm} \times 2 \mathbf{m m ~ S W J}$ actuators. $R e_{c}=500,000$, $\alpha=6^{\circ}, \delta_{f}=40^{\circ}, C_{\mu}=\mathbf{2 . 2 \%}$.

Most of the results presented throughout the remainder of the paper are with the model angle of attack at $8^{\circ}$. Mean vorticity contours with streamlines computed from the PIV results are presented in Fig. 9 and show the changes in the separated region on the flap near $y / s=0.48$ as the momentum of the smaller actuators is increased. The vorticity contours and streamlines of the baseline flowfield provided in Fig. 9(a) show that there is a large recirculation region over the flap. When AFC is applied using a $C_{\mu}$ level of $1.2 \%$ (Fig. 9(b)) separation is delayed thereby reducing the size of the separated region on the flap of the model. When the $C_{\mu}$ level is increased to $2.2 \%$ there are subtle changes to the size of the separated region and the streamlines are deflected closer to the surface of the model as shown in Fig. 9(c). For $C_{\mu}$ levels of $1.2 \%$ and $2.2 \%$, the sweeping jet is seen by the positive vorticity near the leading edge of the flap. At $C_{\mu}=3.0 \%$ shown in Fig. 9(d), the sweeping jet produces a large positive vortex residing on a narrow region of negative vorticity near the surface that extends over half of the length of the flap. Downstream of this region, there is a positive vorticity layer on the flap surface. Figure 9 (e) shows results for a $C_{\mu}$ level of $5 \%$ and is included because it shows the control authority of the SWJ actuators to attach the flow. The large $C_{\mu}$ levels required for flow attachment may be due to the spacing between actuators being too large resulting in regions where the flow is more separated.

\section{C. $2 \mathrm{~mm} \times 4 \mathrm{~mm}$ SWJ Actuator, $\delta_{f}=40^{\circ}$}

Fig. 10 presents pressure distributions obtained with the small, $1 \mathrm{~mm} \times 2 \mathrm{~mm}$ actuator and the large, $2 \mathrm{~mm}$ x $4 \mathrm{~mm}$ actuators at $y / s=0.5$. The flap deflection angle is $40^{\circ}$ and the model is at an angle of attack of $8^{\circ}$. Comparable momentum coefficient levels are shown for the two actuators. The pressure distribution for the baseline flowfield shows that the flow is separated over the flap of the model. For both actuator configurations, a $C_{\mu}$ of $1 \%$ increases circulation upstream of the flap shoulder and increases the pressure over most of the flap surface. A $C_{\mu}$ of $2.9 \%$ generates a significant pressure recovery over the flap at this $y / s$ location when using either actuator. The most significant difference between the two actuators is that the suction peak generated at the flap shoulder by the larger actuator configuration is close to that generated at the leading edge of the model.

Fig. 11(a) presents the variations in $C_{L}$ due to $C_{\mu}$ for the two actuator configurations. The data show 


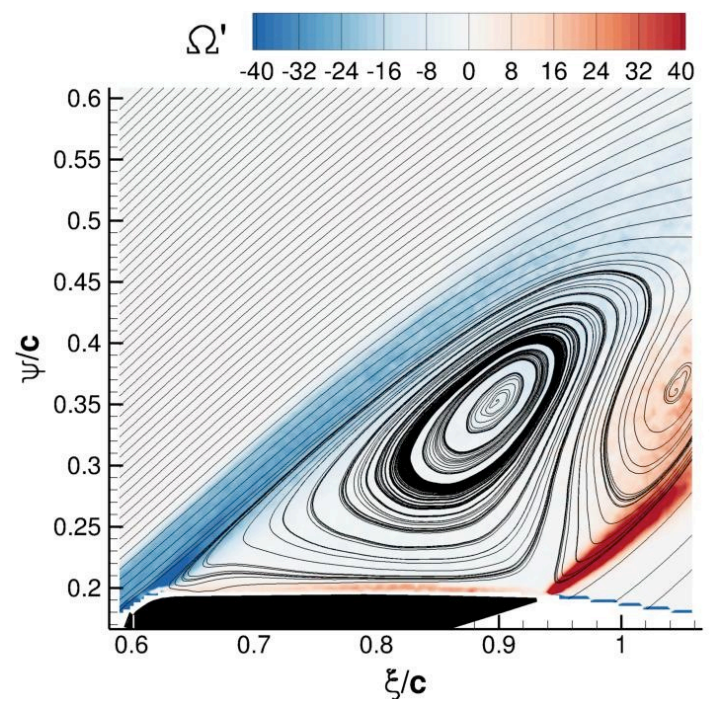

(a) Baseline.

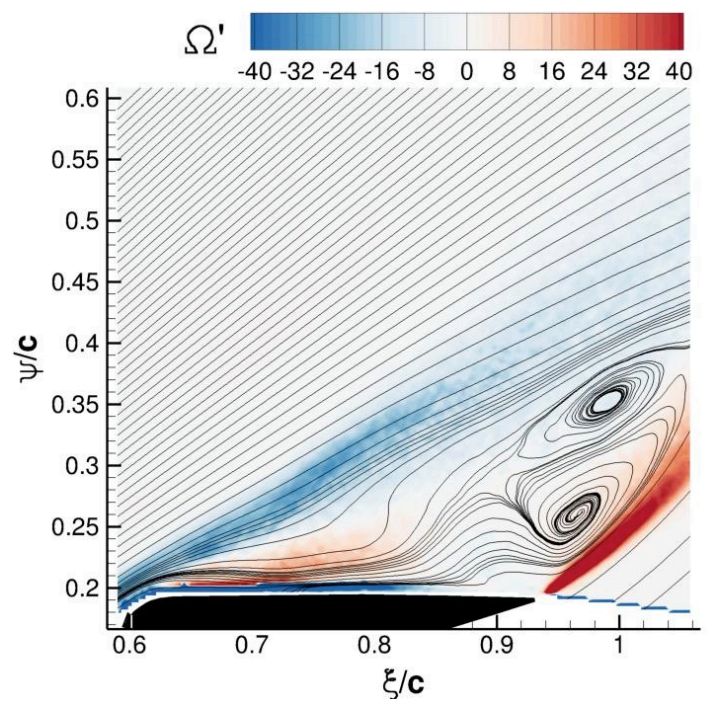

(c) $C_{\mu}=2.2 \%$.

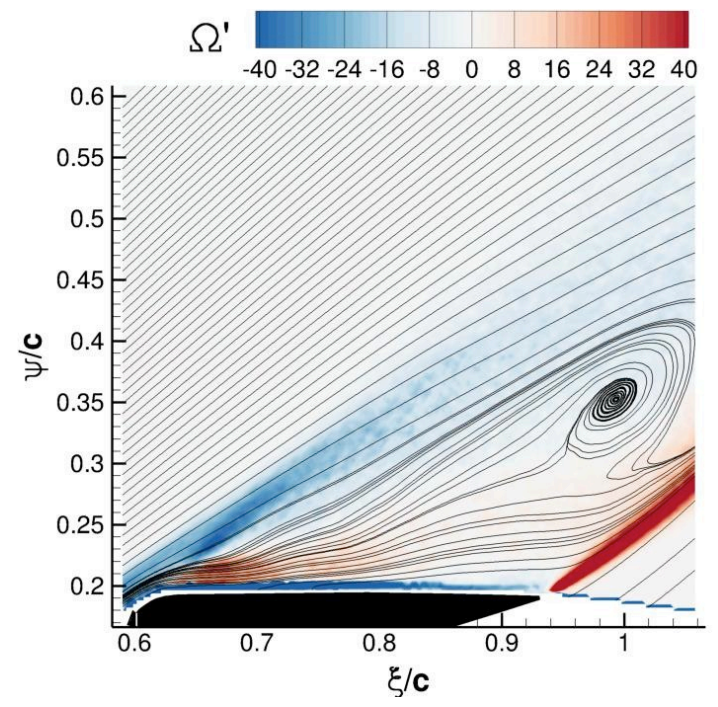

(b) $C_{\mu}=1.2 \%$.

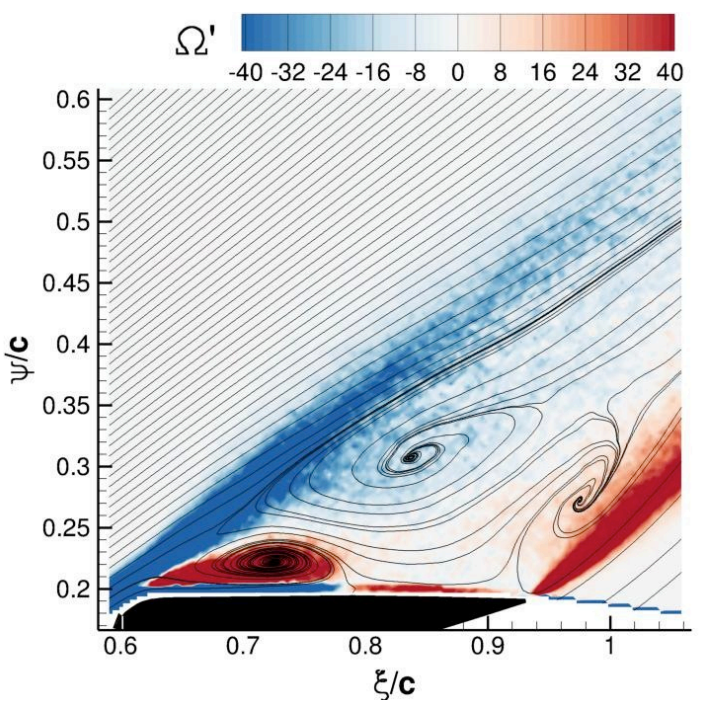

(d) $C_{\mu}=3.0 \%$.

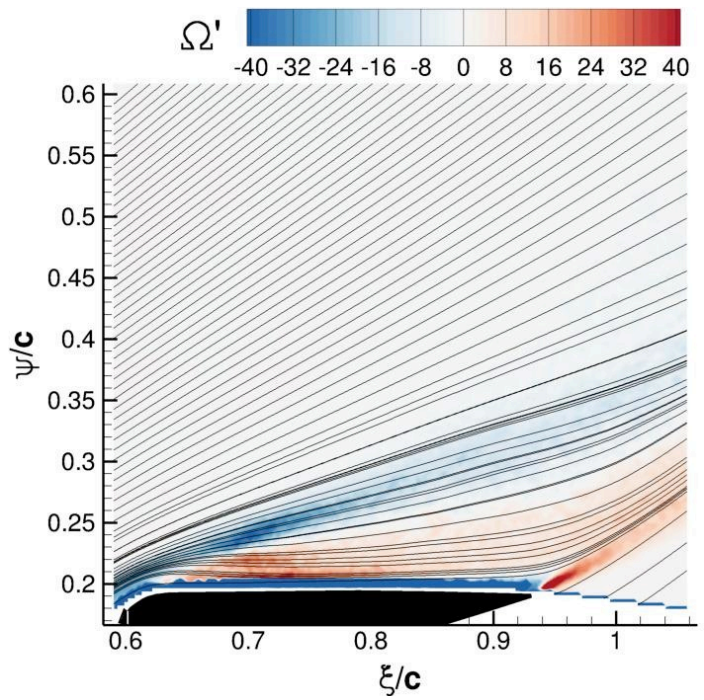

(e) $C_{\mu}=5.0 \%$.

Figure 9. Mean vorticity contours from PIV on the flap data using $1 \mathrm{~mm} \times \mathbf{2} \mathbf{m m ~ S W J}$ actuators. $R e_{c}=500,000$, $\alpha=8^{\circ}, \delta_{f}=40^{\circ}$. 


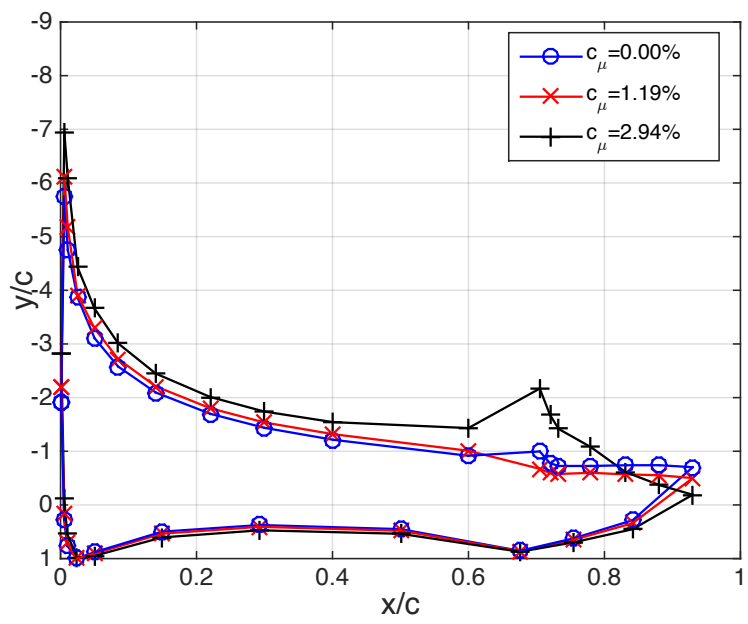

(a) $C_{p}$ distributions for $1 \mathrm{~mm} \times 2 \mathrm{~mm}$ actuators.

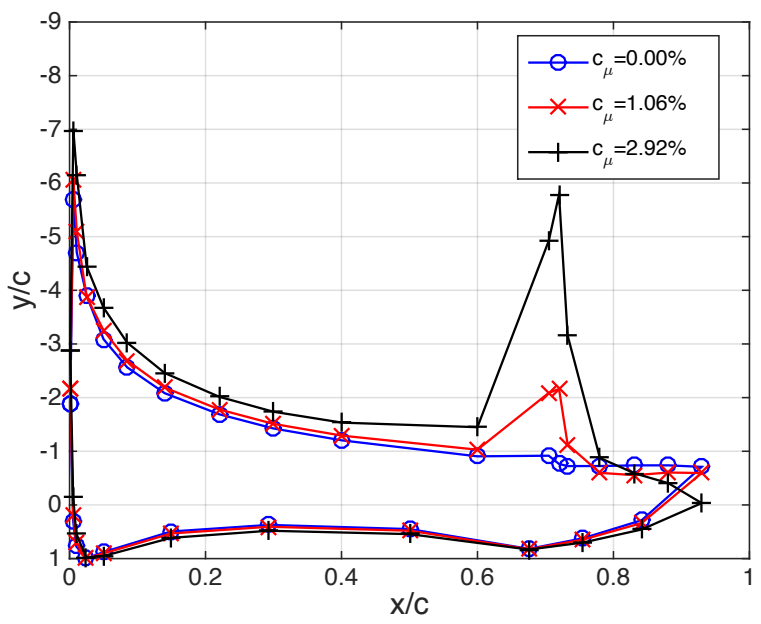

(b) $C_{p}$ distributions for $2 \mathrm{~mm} \times 4 \mathrm{~mm}$ actuators.

Figure 10. $C_{p}$ data comparing the two actuator sizes at $R e_{c}=\mathbf{5 0 0 , 0 0 0 ,} \delta_{f}=40^{\circ}, \alpha=8^{\circ}$, and $y / s=0.5$.

that at low $C_{\mu}$ levels, AFC results in a reduction in lift. Once the $C_{\mu}$ level is above $0.2 \%$ and $0.4 \%$ for the large and small actuator configurations, respectively, lift increases with increasing $C_{\mu}$. The data also show that the larger actuator is more efficient in terms of momentum, i.e., smaller values of $C_{\mu}$ are needed to obtain a given $C_{L}$ using the larger actuators as compared to the smaller actuators. Although there are half as many large actuators in an array, Fig. 11(b) shows that the mass flow required to obtain similar lift values is greater for the large actuators due to the orifice area being double that of the small actuators. Finally, Fig. 11(c) presents $C_{L}$ as a function of $C_{\pi}$ and shows that the larger actuator is more efficient in terms of power where $C_{\pi}=Q * P_{s} /\left(0.5 * \rho * S_{\text {ref }} * U_{\infty}^{3}\right)$. Seele et al. ${ }^{13}$ and Koklu ${ }^{17}$ obtained similar results when they compared the performance of several actuator sizes.

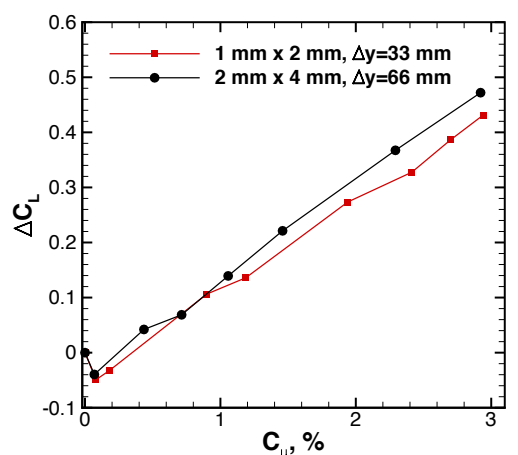

(a) Lift versus $C_{\mu}$.

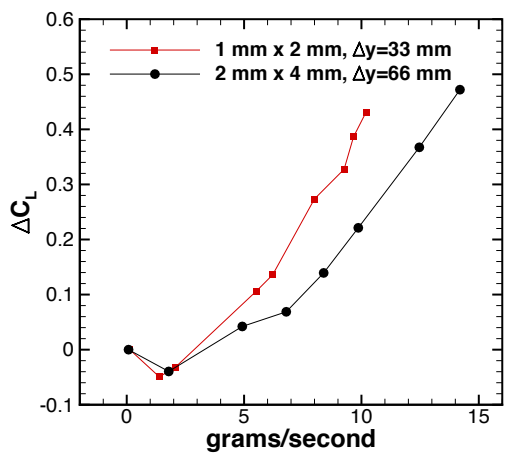

(b) Lift versus mass flow rate.

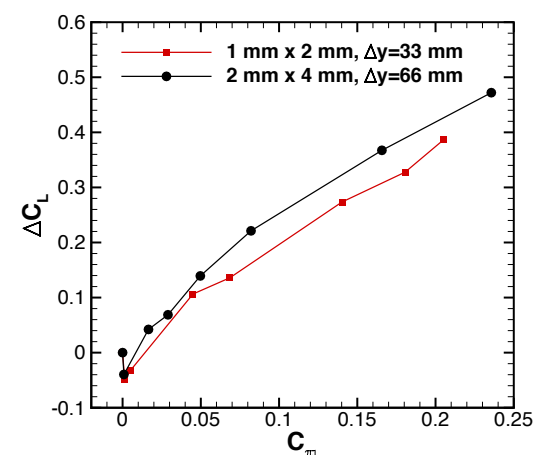

(c) Lift versus $C_{\pi}$.

Figure 11. Lift increment as a function of $C_{\mu}$, mass flow rate, and $C_{\pi}$ comparing the two size actuators at $R e_{c}=\mathbf{5 0 0 , 0 0 0 ,} \delta_{f}=40^{\circ}$, and $\alpha=8^{\circ}$.

Fig. 12 presents vorticity contours obtained at $y / s=0.48$ when using the larger $(2 \mathrm{~mm} \mathrm{x} 4 \mathrm{~mm})$ sweeping jet actuators. $C_{p}$ distributions are also presented for each $C_{\mu}$ value and provide a comparison of the baseline and controlled flowfields at the model center span location, $y / s=0.5$. Note the field of view was adjusted, compared to the PIV results shown in Fig. 9, so that the entire separated region above the flap is captured. The data in Fig. 12(b) is for a $C_{\mu}$ level of $0.23 \%$. While only minor differences are noted in the $C_{p}$ distribution 
in Fig. 12(e), the excitation has altered the recirculation region thereby significantly reducing the bluff body shedding that is detected by the unsteady pressure transducers. As the $C_{\mu}$ level is increased, the SWJ presence is noted by the strong positive vorticity near the leading edge of the flap. In Fig. 12(g), the positive vorticity concentration at the flap shoulder reaches a maximum level at $C_{\mu}=1.44 \%$. As $C_{\mu}$ is increased, the separated shear layer is deflected towards the surface of the model as shown by the vorticity contours of Fig. 12(h) and Fig. 12(i). The shear layer movement towards the surface results in the pressure recovery on the flap shown in Fig. 12(j) and Fig. 12(l).

Fig. 13 presents velocity profiles extracted from the PIV data for the two actuator configurations at different streamwise locations on the flap. The profiles presented in Fig. 13(a) and Fig. 13(d) show that there is no reversed flow at $\xi / c=0.62$, indicating that the flow separates downstream of this location. AFC increases the near wall velocity with the largest increase provided by the $2 \mathrm{~mm} \mathrm{x} 4 \mathrm{~mm}$ at a $C_{\mu}=4.3 \%$ (Fig. 13(d)). At the downstream locations, reversed flow is clearly evident by the negative velocities in the baseline profiles of Fig. 13(b)-Fig. 13(c) and Fig. 13(e)-Fig. 13(f). The near-wall momentum introduced by the SWJ actuators eliminates the reversed flow regions as shown in Fig 13(c) and Fig. 13(f) for the large and small actuator, respectively, however, a significant amount of momentum was required.

To verify that the SWJ actuator spacing of $6.6 \mathrm{~cm}$ provided the necessary control along the span of the model, streamwise planes of PIV data were acquired at several spanwise locations. Figure 14 presents vorticity contours at several $y / s$ locations that cover the region between two adjacent SWJ actuators. The data were acquired using the larger ( $2 \mathrm{~mm} \times 4 \mathrm{~mm}$ ) actuators and the spacing between PIV measurements planes was $8.26 \mathrm{~mm}$. The data in Fig. 14(b) and Fig. 14(c), along with data from mulitiple locations not presented, show that the excitation provided by the SWJ actuators results in almost uniform control of the separated flow between $y / s$ of 0.40 and 0.47 . The vorticity contours at the beginning and end of the survey shown in Fig. 14(a) and Fig. 14(d) indicate that there is more separated flow at these $y / s$ locations. This may be due to the fact that these locations are close to the center of the SWJ actuator.

In addition to the streamwise PIV measurements acquired between two adjacent SWJ actuators, 2D spanwise planes of PIV data were acquired at several streamwise locations along the flap upper surface covering the region between $y / s=0.34$ and $y / s=0.47$. As mentioned previously, the $2 \mathrm{D}$ spanwise PIV data have a large out-of-plane velocity component that increases the errors in the quantities measured. However, the data can be used for qualitative analysis and we use it here to visualize the in-plane vortices generated by the SWJ actuators. Figure 15 presents mean spanwise vorticity contours obtained using the larger $(2$ $\mathrm{mm} \times 4 \mathrm{~mm}$ ) actuators at $C_{\mu}=1.4 \%$ and $C_{\mu}=2.9 \%$. While instantaneous data would show the motion of the sweeping jet across the field of view of the PIV measurements, the mean data presented in Fig. 15(a)Fig. 15(b) and Fig. 15(e)-Fig. 15(g) at $y / s$ less than 0.43 show two adjacent, dominant vortices, one positive and one negative that represent the flow produced by one SWJ actuator. When the flow is attached, the vortices are more concentrated near the flap surface and grow in strength with increasing $\xi / c$. The vortices become more diffuse when the $C_{\mu}$ level used is too low to overcome the adverse pressure gradient and keep the flow from separating (cf. Fig. 15(d)). However, the signature of the vortices produced by the SWJ actuators is still present in the flow as noted by the alternating sign vortices centered around $z / s=0.4$ in Fig. 15(d).

\section{Conclusions}

A candidate sweeping jet actuator for an upcoming high Reynolds number AFC experiment was evaluated in both benchtop and wind tunnel experiments. Arrays of the actuator with $1 \mathrm{~mm} \times 2 \mathrm{~mm}$ exit orifices spaced $3.3 \mathrm{~cm}$ apart were used to control flow separation on the trailing edge flap of a semi-span wing model. The actuator size and spacing are comparable to what is required for the high Reynolds number experiment. The benchtop experiments showed that with an exit orifice of $1 \mathrm{~mm} \times 2 \mathrm{~mm}$, the jet sweep angle, even at a very low supply pressure, is reduced compared to that of the $2 \mathrm{~mm} \mathrm{x} 4 \mathrm{~mm}$ actuator used in this study. Streamwise PIV surveys at a limited number of spanwise locations suggest that the actuator spacing may not be optimal for the small actuator. Wind tunnel results show that the sweeping jet actuator is capable of controlling separation on this model geometry at Mach numbers up to 0.1 but the jet speeds approach sonic conditions. However, since the actuators will need to control separation at even higher Mach numbers and flap deflection angles, this size actuator would not provide the most efficient active flow control system.

An actuator twice the size of the smaller actuator was also tested. Due to actuator size, the actuators in the array were spaced $6.6 \mathrm{~cm}$ apart. The larger actuator was able to control the separation on the model 


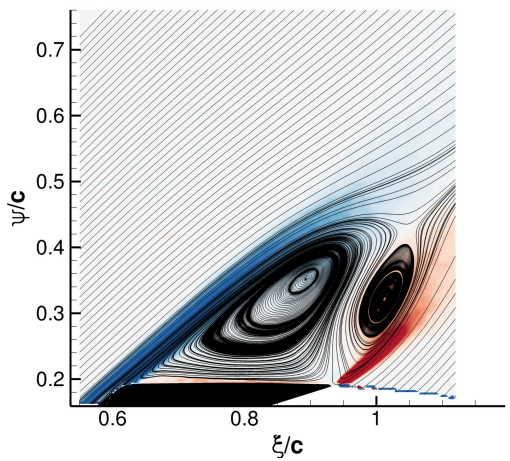

(a) Baseline.

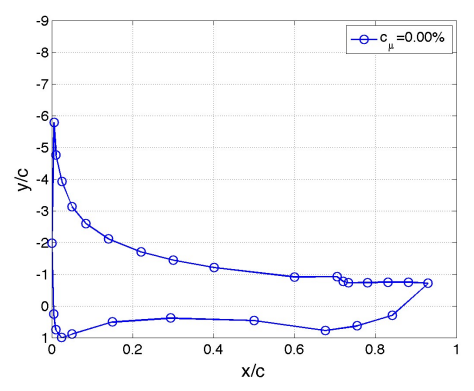

(d) $C_{p}$, Baseline.

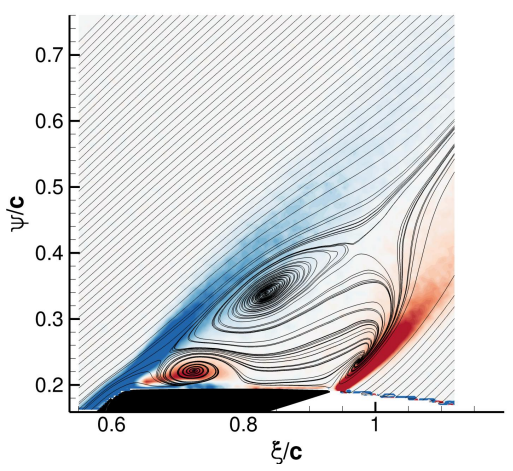

(g) $C_{\mu}=1.44 \%$.

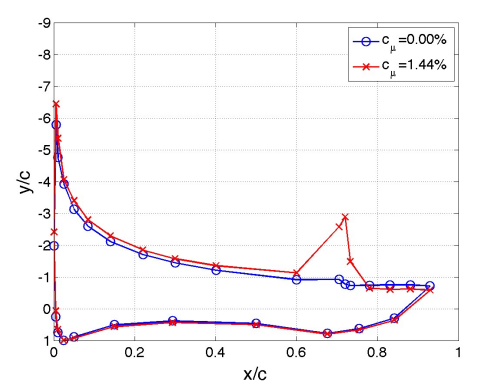

(j) $C_{p}, C_{\mu}=1.44 \%$.

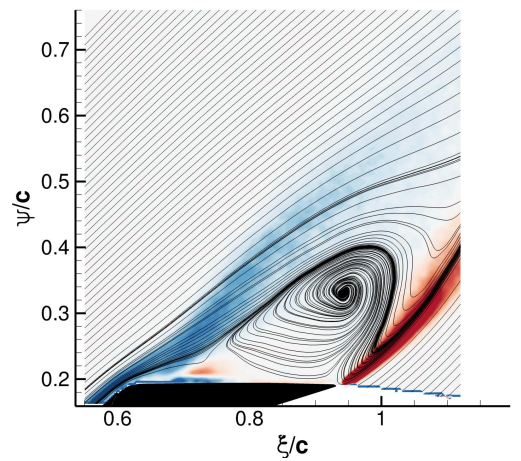

(b) $C_{\mu}=0.23 \%$.

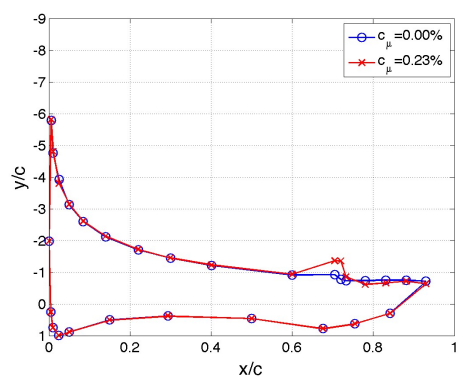

(e) $C_{p}, C_{\mu}=0.23 \%$.

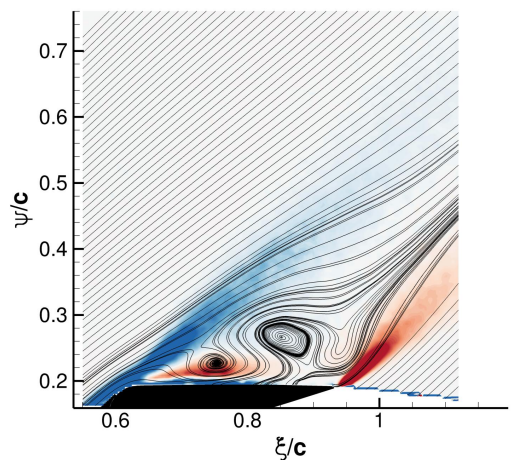

(h) $C_{\mu}=2.32 \%$.

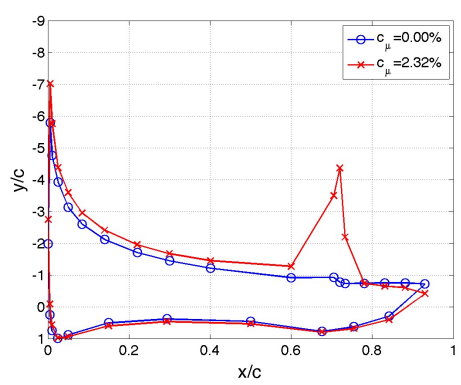

(k) $C_{p}, C_{\mu}=2.32 \%$.

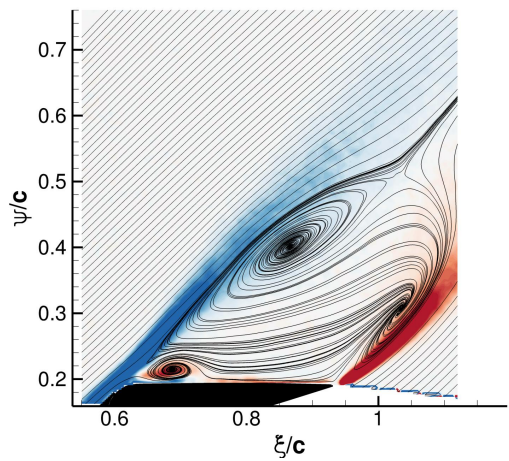

(c) $C_{\mu}=0.46 \%$.

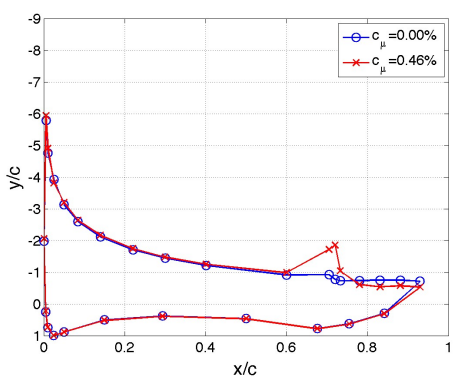

(f) $C_{p}, C_{\mu}=0.46 \%$.

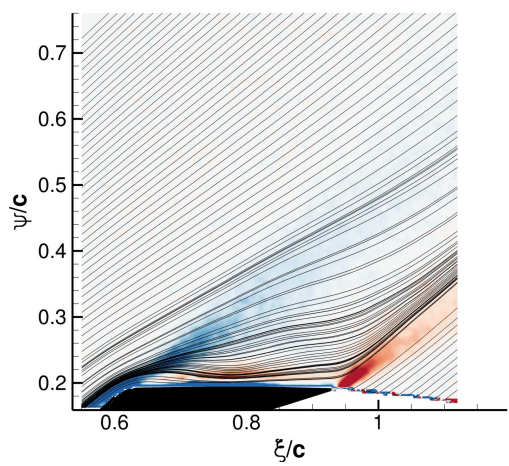

(i) $C_{\mu}=2.92 \%$.

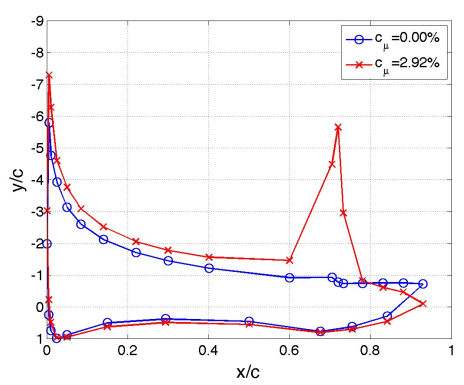

(l) $C_{p}, C_{\mu}=2.92 \%$.

Figure 12. Mean vorticity contours from PIV data on the model flap. $R e_{c}=500,000, \alpha=8^{\circ}, \delta_{f}=40^{\circ}$. 


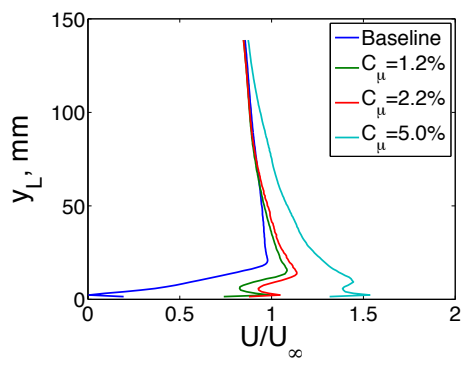

(a) $1 \mathrm{~mm} \times 2 \mathrm{~mm} \mathrm{SWJ}, \xi / c=0.62$.

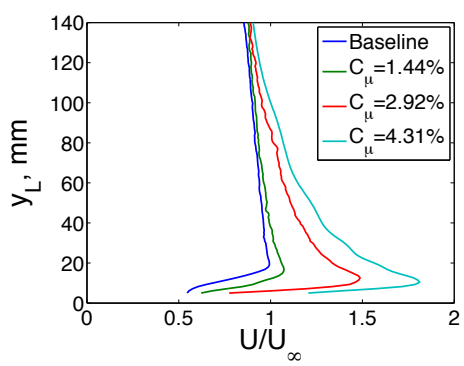

(d) $2 \mathrm{~mm} \times 4 \mathrm{~mm} \mathrm{SWJ}, \xi / c=\mathbf{0 . 6 2}$.

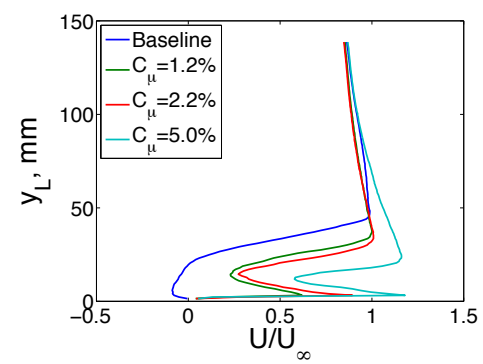

(b) $1 \mathrm{~mm} \times 2 \mathrm{~mm} \mathrm{SWJ,} \xi / c=0.72$.

(c) $1 \mathrm{~mm} \times 2 \mathrm{~mm} \mathrm{SWJ,} \xi / c=0.92$.
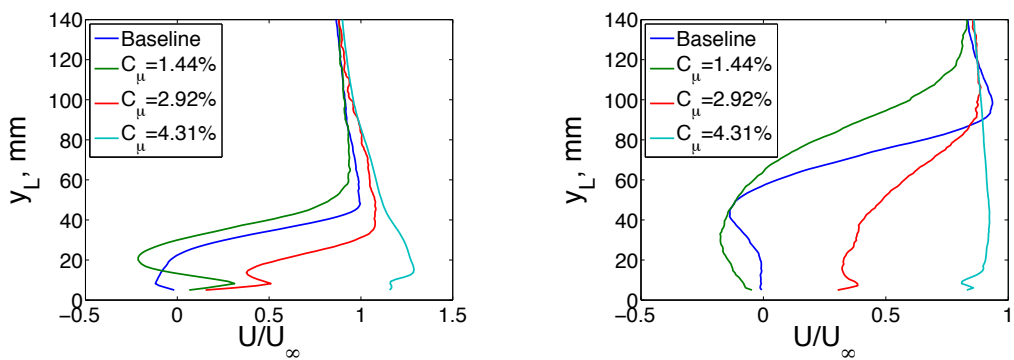

(e) $2 \mathrm{~mm} \times 4 \mathrm{~mm} \mathrm{SWJ,} \xi / c=0.72$.

(f) $2 \mathrm{~mm} \times 4 \mathrm{~mm} \mathrm{SWJ}, \xi / c=0.92$.

Figure 13. Boundary layer profiles from PIV measurements at $y / s=\mathbf{0 . 4 8} . R e_{c}=\mathbf{5 0 0 , 0 0 0 ,} \alpha=8^{\circ}, \delta_{f}=40^{\circ}$.

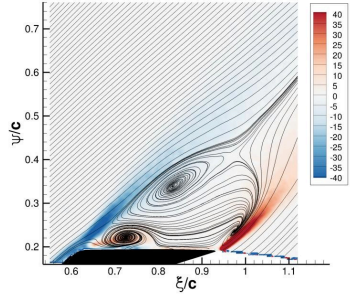

(a) $y / s=\mathbf{0 . 4 8}$.

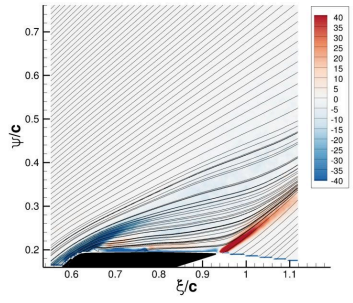

(b) $y / s=\mathbf{0 . 4 5}$.

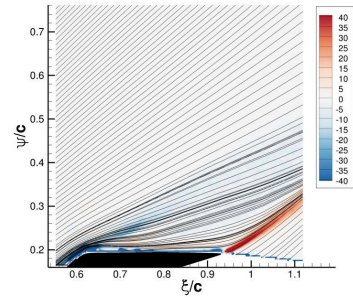

(c) $y / s=\mathbf{0 . 4 1}$.

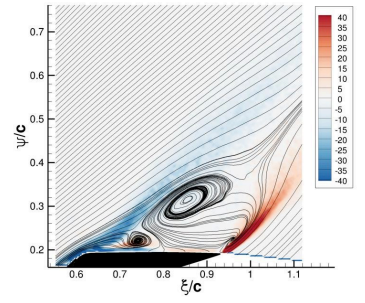

(d) $y / s=\mathbf{0 . 3 8}$.

Figure 14. Mean vorticity contours from PIV data using the $2 \mathrm{~mm} \times 4 \mathrm{~mm}$ actuators with $C_{\mu}=1.44 \%$.

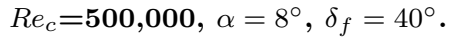




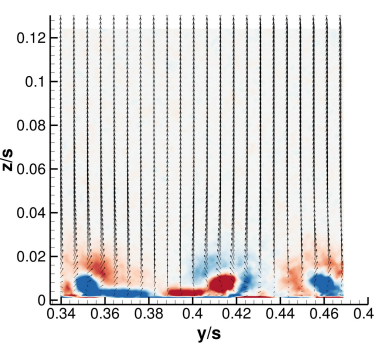

(a) $\xi / c=0.67, C_{\mu}=\mathbf{1 . 4 4 \%}$.

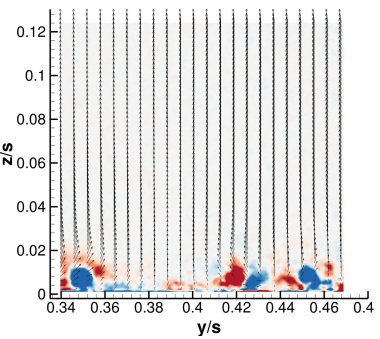

(e) $\xi / c=\mathbf{0 . 6 7}, C_{\mu}=2.92 \%$.

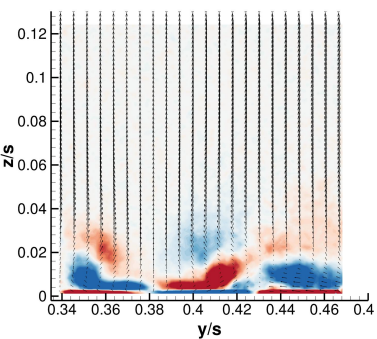

(b) $\xi / c=0.71, C_{\mu}=\mathbf{1 . 4 4 \%}$.

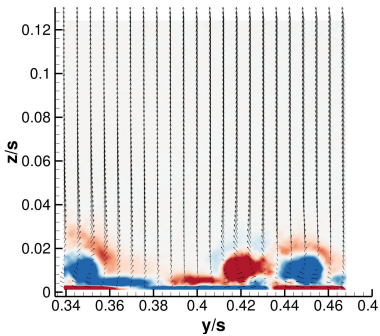

(f) $\xi / c=\mathbf{0 . 7 1}, C_{\mu}=2.92 \%$.

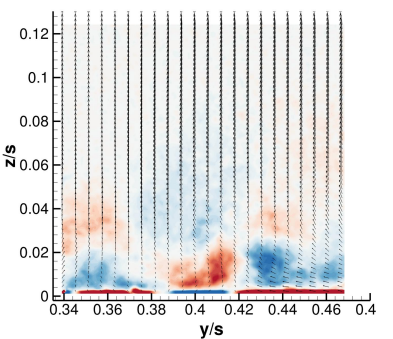

(c) $\xi / c=0.75 . C_{\mu}=\mathbf{1 . 4 4 \%}$.

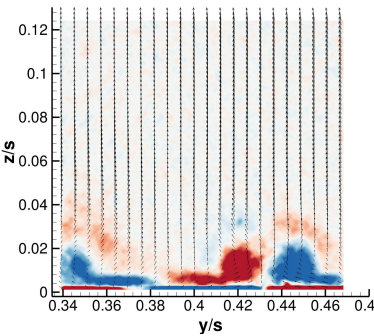

(g) $\xi / c=\mathbf{0 . 7 5}, C_{\mu}=2.92 \%$.

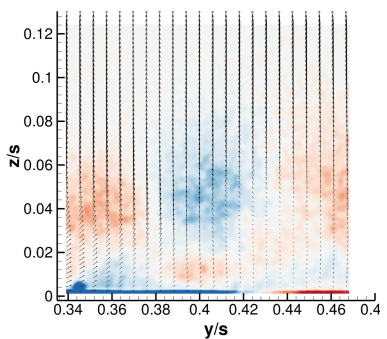

(d) $\xi / c=\mathbf{0 . 8 0}, C_{\mu}=\mathbf{1 . 4 4 \%}$.

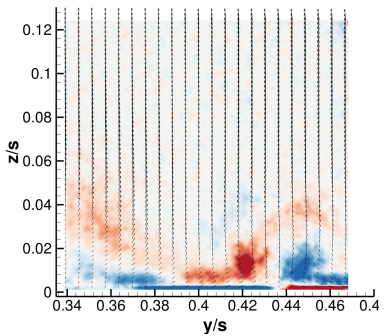

(h) $\xi / c=\mathbf{0 . 8 0}, C_{\mu}=2.92 \%$.

Figure 15. Mean vorticity contours from spanwise PIV data using the $2 \mathrm{~mm} \times 4 \mathrm{~mm}$ actuators. $R e_{c}=500,000$, $\alpha=8^{\circ}, \delta_{f}=40^{\circ}$.

with lower $C_{\mu}$ values. Although, the mass flow requirements for this AFC actuator assembly were larger, the momentum and power requirements were lower. The larger actuator studied generated a much higher suction peak at the flap shoulder. Particle Image Velocimetry data provide insight into how the jet interacts with the separated flowfield via streamwise vortices produced by the sweeping jets and ultimately attaches the flow to the flap surface. The maximum Mach number tested with these actuators was $M=0.07$. At these conditions the sweeping jet was incompressible. The lower input pressures suggest that this size actuator might be better for controlling separation in the upcoming high Reynolds number wind tunnel experiment.

\section{Acknowledgments}

The authors would like to thank the Advanced Air Transport Technology Project of the NASA Fundamental Aeronautics Program for funding the research and the following individuals for their support; Catherine McGinley, Luther Jenkins, John C. Lin, Judi Hannon, Norman Schaeffler, Donald, Day, Christal Kellam, and Charlie Debro. Thanks are also extended to Mark Fletcher, Luther Jenkins, and Chung-sheng Yao for help with the PIV acquisition and analysis. The authors also thank model designer Sandy Webb for his work on the model spar modifications and sweeping jet actuator arrays. Thanks are extended to Wayne Geouge, Tom Hall, Kevin McLain, Robert Andrews, and Gary Wainwright for help with various aspects of the model fabrication and instrumentation process.

\section{References}

\footnotetext{
${ }^{1}$ Martin, P. B., Overmeyer, A. D., Tanner, P. E., Wilson, J. S., and Jenkins, L. N., "Helicopter Fuselage Active Flow Control in the Presence of a Rotor," American Helicopter Society 70th Annual Forum, Paper 335, Montréal, Québec, Canada, 2014.

${ }^{2}$ Seifert, A., Stalnov, O., Sperber, D., Arwatz, G., Palei, V., David, S., Dayan, I., and Fono, I., "Large Trucks Drag Reduction Using Active Flow Control," AIAA Paper 2008-0743, Jan. 2008.

${ }^{3}$ Wilson, J., Schatzman, D., Arad, E., Seifert, A., and Shtendel, T., "Suction and Pulsed-Blowing Flow Control Applied to an Axisymmetric Body," AIAA Journal, Vol. 51, No. 10, 2013, pp. 2432-2446.
} 
${ }^{4}$ Cerretelli, C., Wuerz, W., and Gharaibah, E., "Unsteady Separation Control on Wind Turbine Blades using Fluidic Oscillators," AIAA Journal, Vol. 48, No. 7, July 2010, pp. 1302-1311.

${ }^{5}$ Pack Melton, L. G., "Active Flow Separation Control on a NACA 0015 Wing using Fluidic Actuators," 7th AIAA Flow Control Conference, American Institute of Aeronautics and Astronautics, Reston, Virginia, June 2014, pp. 1-16.

${ }^{6}$ Gregory, J. W. and Tomac, M., "A Review of Fluidic Oscillator Development and Application for Control," AIAA Paper 2013-2474, 2013.

${ }^{7}$ Andino, M. Y., Lin, J. C., Washburn, A. E., Whalen, E. A., Graff, E. C., and Wygnanski, I. J., "Flow Separation Control on a Full-Scale Vertical Tail Model using Sweeping Jet Actuators," 53rd AIAA Aerospace Sciences Meeting, American Institute of Aeronautics and Astronautics, Reston, Virginia, Jan. 2015, pp. 1-15.

${ }^{8}$ Whalen, E. A., Lacy, D. S., Lin, J. C., Andino, M. Y., Washburn, A. E., Graff, E. C., and Wygnanski, I. J., "Performance Enhancement of a Full-Scale Vertical Tail Model Equipped with Active Flow Control," 53rd AIAA Aerospace Sciences Meeting, American Institute of Aeronautics and Astronautics, Reston, Virginia, Jan. 2015, pp. 1-11.

${ }^{9}$ Moon, M., "NASA and Boeing to test eco-friendly technologies for airplanes@http://www.engadget.com/2015/04/03/nasaboeing-era-eco-friendly-planes/," April 2015.

${ }^{10}$ Vatsa, V., Koklu, M., and Wygnanski, I., "Numerical Simulation of Fluidic Actuators for Flow Control Applications," 6th AIAA Flow Control Conference, American Institute of Aeronautics and Astronautics, Reston, Virigina, Sept. 2012, pp. $1-18$.

${ }^{11}$ Koklu, M. and Melton, L., "Sweeping Jet Actuator in a Quiescent Environment," AIAA Paper 2013-2477, June 2013.

${ }^{12}$ Koklu, M., "The Effects of Sweeping Jet Actuator Parameters on Flow Separation Control," 45th AIAA Fluid Dynamics Conference, American Institute of Aeronautics and Astronautics, Reston, Virginia, June 2015, pp. 1-19.

${ }^{13}$ Seele, R., Graff, E., Gharib, M., Taubert, L., Lin, J., and Wygnanski, I., "Performance Enhancement of a Vertical Tail Model with Sweeping Jet Actuators," AIAA Paper 2013-0411, Jan. 2013.

${ }^{14}$ Greenblatt, D. and Washburn, A., "Influence of Finite Span and Sweep on Active Flow Control Efficacy," AIAA Journal, Vol. 46, No. 7, 2008, pp. 1675-1694.

${ }^{15}$ Greenblatt, D., "Dual Location Separation Control on a Semispan Wing," AIAA Journal, Vol. 45, No. 8, 2007, pp. 18481860. 2005.

${ }^{16}$ Greenblatt, D., "Management of Vortices Trailing Flapped Wings via Separation Control," AIAA Paper 2005-0061, Jan.

${ }^{17}$ Koklu, M. and Owens, L. R., "Flow Separation Control Over a Ramp Using Sweeping Jet Actuators," 7th AIAA Flow Control Conference, American Institute of Aeronautics and Astronautics, Reston, Virginia, June 2014, pp. 1-20.

${ }^{18}$ Wernet, M. P., "Fuzzy Logic Enhanced Digital PIV Processing Software," 18th International Congress on Instrumentation for use in Aerospace Simulation Facilities 2010-4247, June 1999.

${ }^{19}$ Scarano, F. and Riethmuller, M., "Advances in Iterative Multigrid PIV Image Processing," Experiments in Fluids Supplemental, Vol. 29, 2000, pp. S51-S60.

${ }^{20}$ Melton, L., Hannon, J., Yao, C., and Harris, J., "Active Flow Control at Low Reynolds Numbers on a NACA 0015 Airfoil," AIAA Paper 2008-6407, Aug. 2008. 